\title{
CONSIDERAÇÕES ACERCA DA REGULAÇÃO E SUPERVISÃO DO ENSINO SUPERIOR NO BRASIL
}

\author{
CONSIDERATIONS ABOUT THE REGULATION AND SUPERVISION OF HIGHER \\ EDUCATION IN BRAZIL
}

\author{
Francisco Nilton Gomes de Oliveira \\ Doutor em Linguística pela Universidade Federal de Pernambuco, \\ Mestre em Psicologia pela Universidade de Fortaleza, \\ niltonufrj@gmail.com
}

\author{
Bruna de Pietro Zorzi \\ Especialista em Alfabetização e Letramento pelo Centro Universitário Internacional (UNINTER) \\ bruna_zorzi@hotmail.com \\ Josiane Bertoldo Piovesan \\ Graduada em Terapia Ocupacional pela Universidade Federal de Santa Maria - UFSM. \\ josiane_piovesan@hotmail.com
}

\begin{abstract}
Resumo: O objetivo deste artigo é analisar os processos avaliativos instituídos pelo Sistema Nacional de Avaliação do Ensino Superior (SINAES), sob o olhar de gestores de Instituições de Ensino Superior (IES) privadas brasileiras, de vários estados do país, que responderam a questionário fechado: reitores, diretores, pró-reitores, procuradores institucionais e coordenadores de curso. $\mathrm{O}$ artigo é oriundo de projeto de pesquisa que analisou processos de incorporação, fusão e aquisição na educação superior do país. Implantado em 2004, o Sistema é formado por três componentes principais de avaliação: instituições, cursos e desempenho dos estudantes. A coleta de dados ocorreu no período de agosto/2017 a março/2018. As análises evidenciam as inquietudes desses gestores, derivadas da não concordância com o modelo de avaliação da educação superior aplicado pelo Ministério da Educação (MEC). Conclui-se que o SINAES é um instrumento meramente técnico e fácil de ser burlado na incessante busca de um conceito satisfatório à IES e ao curso de graduação. Por fim, questiona-se a necessidade de as autoridades públicas responsáveis pela avaliação do sistema federal de educação superior apresentarem à sociedade brasileira os desafios postos ao setor no Brasil contemporâneo.
\end{abstract}

Palavras-Chave: Avaliação. Educação superior. Regulação. Supervisão.

Abstract: The aim of this article is to analyze the evaluation processes instituted by the National Higher Education Evaluation System (SINAES), under the eyes of managers of Brazilian private higher education institutions (HEIs), from various states of the country, who answered a closed questionnaire: deans, directors, deans, institutional prosecutors and course coordinators. The article comes from a research project that analyzed processes of incorporation, merger and acquisition in higher education in the country. Implemented in 2004, the System consists of three main evaluation components: institutions, courses and student performance. Data collection occurred from August / 2017 to March / 2018. The analyzes show the concerns of these managers, derived from the disagreement with the higher education evaluation model applied by the Ministry of Education (MEC). It is concluded that the SINAES is a merely technical instrument and easy to be circumvented in the incessant search for a satisfactory concept to the HEI and the undergraduate course. Finally, we question the need for the public authorities responsible for evaluating the federal higher education system to present to Brazilian society the challenges posed to the sector in contemporary Brazil.

Keywords: Evaluation. High education. Regulation. Supervision.

\section{Para citar - (ABNT NBR 6023:2018)}

OLIVEIRA, Francisco Nilton Gomes de; ZORZI, Bruna de Pietro; PIOVESAN, Josiane Bertoldo. Considerações acerca da Regulação e Supervisão do Ensino Superior no Brasil. Eccos - Revista Cientifica, São Paulo, n. 52, p. 1-18, e10754, jan./mar. 2020. Disponível em: https://doi.org/10.5585/eccos.n52.10754. 


\section{Introdução}

Este artigo é um recorte de uma pesquisa sobre as incorporações, fusões e aquisições na Educação Superior do Brasil, vinculado ao grupo de pesquisa da Universidade Federal de Santa Maria (UFSM), denominado Política, Avaliação e Gestão da Educação Superior, sob a coordenação do Professor Doutor Francisco Nilton Gomes de Oliveira, que está vinculado ao programa de Pós-Graduação em Educação Profissional e Tecnológica da UFSM. O presente papper foi tecido com os orientandos do referido programa.

O objetivo dessas considerações é discernir os processos avaliativos decorrentes por meio do Sistema Nacional de Avaliação do Ensino Superior - SINAES e o olhar de gestores de Instituições de Ensino Superior, privadas e públicas, no Brasil, no que diz respeito aos processos avaliativos permeados a partir do SINAES.

Reverberar a avaliação vinculada ao Ensino Superior no Brasil é tecer uma historiografia de fatos decorrentes da implantação e implementação deste nível de ensino no nosso país. Neste condão, rememora-se que a universidade originou-se no Brasil, no final do século IXX, atendendo, à época, à burguesia brasileira. $\mathrm{O}$ acesso ao Ensino Superior era limitado a poucos que, porventura, possuíam posses econômicas, havendo uma predominância no atendimento à elite brasileira da época. Nesse mote, não havia uma preocupação dos gestores em avaliar a qualidade do ensino, doravante o modelo vigia os preceitos econômicos ainda pautados num paradigma de ensino europeu, nos moldes da produção. O conhecimento era visto como produto para atender à Ciência e às necessidades das classes mais favorecidas.

Nos idos dos anos de 1970, no Brasil, quando a história relata as avaliações institucionais internas, realizadas de forma incipiente, por poucas Instituições de Ensino Superior, sem haver preocupação em relação ao acompanhamento e ao controle do Estado. De qualquer forma, as experiências de algumas IES foram norteadoras e reflexivas para se discutir a importância da avaliação no Ensino Superior e a criação, por meio do Estado, de marcos regulatórios, supervisão e regulação da educação superior.

A partir dos anos 90, a avaliação se deu através do Exame Nacional de Cursos, como uma experiência pioneira para avaliar a qualidade do alunado do Ensino Superior. Esta práxis foi uma mola propulsora para o Estado criar parâmetros técnicos de instrumentalização da qualidade na Educação Superior.

O SINAES no Brasil é um sistema pioneiro para a regulação da Educação Superior, bem como é um dispositivo que supervisiona, acompanha e controla a qualidade desta educação. A 
criação do e-MEC e o banco de avaliadores da Educação Superior - BASIS ratifica o acompanhamento do Estado.

O ponto de partida dos pesquisadores teve origem das inquietudes em relação à avaliação, daí a necessidade da investigação, buscando o olhar de gestores universitários sobre o instrumento - SINAES.

\section{Balizadores teóricos}

Realizando uma análise histórica, a avaliação da Educação Superior teve início na década de 70, quando a Coordenação de Aperfeiçoamento de Pessoal de Ensino Superior (CAPES) foi instituída com a política de avaliação da Pós-Graduação, voltada para os cursos de mestrado e doutorado (POLIDORI et al., 2006).

Em 1983, iniciou-se a avaliação dos cursos de graduação, a partir do estabelecimento do Programa de Avaliação da Reforma Universitária (PARU), pelo Ministério da Educação (MEC), o qual tinha como objetivo enfatizar a gestão das Instituições de Ensino Superior - IES (POLIDORI et al., 2006). A priori, essa proposta se baseava numa visão de cunho administrativo, a base metodológica da avaliação distanciava-se dos preceitos pedagógicos. Não se buscava a qualidade do ensino, muito menos a qualidade das Instituições de Ensino Superior. Para essa ruptura de prática da avaliação engendrada no viés puramente administrativo desencadeou-se no Brasil um modelo de avaliação a partir de uma proposta de nivelar as instituições em termos de qualidade administrativa e acadêmica, originando assim o Sistema Nacional de Avaliação da Educação Superior (SINAES) (POLIDORI et al., 2006).

Em 2004, o SINAES foi implantado por meio da Lei $\mathrm{n}^{\circ} 10.861$, de 14 de abril de 2004. O Sistema Nacional de Avaliação da Educação Superior (SINAES) é formado por três componentes principais: a avaliação das instituições, dos cursos e do desempenho dos estudantes. O SINAES instaurou o seu uso sistemático para a análise crítica da realidade da Educação Superior no Brasil.

Da avaliação resulta a descrição do curso, com suas dificuldades e potencialidades, numa perspectiva histórica, situando-o nos contornos sociais, políticos e econômicos do Estado e do País. A avaliação - isto é, o estudo, a escuta, a reflexão e o debate em torno do trabalho pedagógico -, aparece então como elemento que propicia caminhos mais seguros para a sistematização de mudanças nas IES e nos cursos de graduação.

O objetivo do SINAES é assegurar o processo nacional de avaliação da IES, de cursos de graduação e do desempenho acadêmico dos estudantes, buscando a melhoria da qualidade do 
ensino superior no país. Os resultados da avaliação devem subsidiar os processos de regulação e supervisão da educação superior que compreendem as ações de autorização, reconhecimento e renovação de reconhecimento de cursos de graduação, e credenciamento e recredenciamento de IES (POLIDORI, 2009, p. 445).

O SINAES possui uma série de instrumentos complementares: autoavaliação, avaliação externa, Exame Nacional de Desempenho dos Estudantes (ENADE), avaliação dos cursos de graduação e instrumentos de informação como o censo e o cadastro (LEI n $\left.{ }^{\circ} 10.861 / 2004\right)$. O nexo dos instrumentos admite que constituam impostos, alguns conceitos, classificados numa escala com cinco níveis, a cada uma das dimensões e ao contíguo das dimensões avaliadas.

Por se tratar de uma lei federal, o SINAES representa agora uma política de Estado para a avaliação das instituições de Ensino Superior brasileiras, a orientar as políticas de governo para tal fim. Os princípios fundamentais do SINAES, conforme a Lei $\mathrm{n}^{\circ}$ 10.861/2004, definem os seguintes princípios:

- Responsabilidade social com a qualidade da Educação Superior;

- Reconhecimento da diversidade do sistema;

- Respeito à identidade, à missão e à história das instituições;

- Globalidade, isto é, compreensão de que a instituição deve ser avaliada a partir de um conjunto significativo de indicadores de qualidade, vistos em sua relação orgânica e não de forma isolada;

- Continuidade do processo avaliativo.

O SINAES integra três modalidades de instrumentos de avaliação, a serem aplicados em diferentes momentos:

1 - Avaliação das Instituições de Educação Superior (Avalies) - é o centro de referência e articulação do sistema de avaliação que se desenvolve em duas etapas principais:

a) autoavaliação - coordenada pela Comissão Própria de Avaliação (CPA) de cada IES, a partir de setembro de 2004;

b) avaliação externa - realizada por comissões designadas pelo Instituto Nacional de Estudos e Pesquisas Educacionais Anísio Teixeira - INEP, segundo diretrizes estabelecidas pela Comissão Nacional de Avaliação da Educação Superior - CONAES.

2 - Avaliação dos cursos de graduação - avalia os cursos de graduação por meio de instrumentos e procedimentos que incluem visitas, in loco, de comissões externas. A periodicidade desta avaliação depende diretamente do processo de reconhecimento e renovação de reconhecimento ao qual os cursos estão sujeitos. 
3 - Avaliação do desempenho dos estudantes (Exame Nacional de Avaliação de Desempenho dos Estudantes - ENADE) - aplica-se aos estudantes no último ano do curso, estando prevista a utilização de procedimentos.

A iniciativa do MEC/INEP, ao desencadear um processo avaliativo, tendo como base norteadora o SINAES, expressa o reconhecimento da urgência desse processo e, ao mesmo tempo, a decisão de tomar a si a responsabilidade de desenvolvê-lo. É que a avaliação permite revisar o desempenho das funções acadêmica, social e política das IES e, concomitantemente, de um curso, na ótica dos seus principais agentes (gestores, alunos e professores).

O procedimento de avaliação proposto por meio do SINAES é abstruso, e para alcançar o objetivo são necessárias aptidões em processos de mensuração e investigação, apreensão do contexto e do conteúdo do objeto da avaliação. Estes parâmetros são os maiores desafios que as IES enfrentam para lidar com o sistema.

Essa metodologia passou a ser desenvolvida através de um conjunto de ações voltadas à: descrição e análise crítica da realidade das IES e dos cursos, construção de soluções acadêmicas e administrativas na IES, bem como implantação e avaliação sistemática dessas soluções. O processo de autoavaliação fundamenta-se na necessidade de promover a melhoria da qualidade da Educação Superior, a orientação da expansão da sua oferta, o aumento permanente da sua eficácia institucional, da sua efetividade acadêmica e social e, especialmente, do aprofundamento dos seus compromissos e responsabilidades sociais. A autoavaliação dar-se-á por meio da Comissão Própria de Avaliação (CPA).

A Comissão Própria de Avaliação é um processo que contempla o acompanhamento e controle de uma IES, dentro de uma abordagem construtiva e dialógica. A avaliação deve ter sempre por princípio a melhoria contínua dos processos acadêmicos e administrativos visando impulsionar a instituição no seu percurso de crescimento e/ou consolidação.

A avaliação e a qualidade estão associadas de forma indissociável, dentro de uma ótica construtiva. Para que haja uma atenção sistemática, estruturada e contínua à qualidade, em termos de conservá-la e desenvolvê-la, é necessário que haja uma atividade estruturada que conduza ao julgamento da qualidade dos processos acadêmicos e de gestão da IES.

Segundo Dias Sobrinho (2008), avaliação é um processo predominantemente qualitativo, embora quantitativo, na medida em que utiliza dados quantitativos. Todavia, ela não pode basear-se somente na mensuração de resultados e de aspectos quantitativos tais como titulação e regime de trabalho dos docentes, relação aluno/docente, índices de evasão escolar, relação m2/aluno nas salas e laboratórios, entre outros, sob pena de ser levada a um modelo 
excessivamente instrumentalista e cartesiano, que corre o risco de privilegiar o produto em detrimento do processo. Torna-se necessário contemplar os processos e considerar o contexto em que os processos se desdobram.

O processo de avaliação deve estar alinhado às definições institucionais, de modo que seu projeto ancora-se em critérios de qualidade que assegurem um fazer acadêmico coerente com os princípios filosóficos que norteiam a concepção de ensino, pesquisa e extensão da Instituição (OLIVEIRA, 2014).

A avaliação institucional visa identificar a eficiência de execução dos propósitos institucionais, refletidos na missão, vocação e objetivos institucionais. De uma forma extremamente articulada, o Projeto Pedagógico Institucional, PPI, deve conter as políticas e programas institucionais, para cumprir tais propósitos no que tange aos aspectos acadêmicos de ensino, de pesquisa e de extensão, e que integra o próprio Plano de Desenvolvimento Institucional, PDI, que traz o planejamento institucional com o estabelecimento de objetivos, metas e ações para cumprir o PPI.

Neste contexto, a articulação entre o planejamento e a avaliação tem um papel muito importante, especialmente no que tange aos processos, resultados e eficácia da autoavaliação institucional.

Além da qualidade do próprio Projeto Pedagógico do curso e do seu processo de execução, devem ser analisados o porte da organização institucional e o aporte da engrenagem administrativa, que disciplinam as ofertas das atividades inerentes ao PPI e fornecem meios para o desenvolvimento destas, o corpo social que as executa (docentes e técnicoadministrativos) ou que incorpora os resultados da sua execução (discentes e egressos) e a infraestrutura física e logística que dá suporte ao desenvolvimento de tais atividades.

Segundo Ristoff (2004), dentro de um processo de avaliação é extremamente importante considerar também os aspectos relativos à sustentabilidade financeira, tendo em vista a continuidade e o impacto social da oferta da Educação Superior.

As dimensões de avaliação devem incluir, ainda, a responsabilidade social da instituição, especialmente no que se refere à sua contribuição para a inclusão social, o desenvolvimento econômico e social, a defesa do meio ambiente, a memória cultural, a produção artística e o patrimônio cultural.

Desta forma, ficam configuradas as seguintes dimensões, a serem acompanhadas pela comissão própria de avaliação: a missão e o Plano de Desenvolvimento Institucional - PDI; Projeto Pedagógico Institucional - PPI; Responsabilidade Social; Políticas de pessoal; Organização e gestão institucionais; infraestrutura física e logística; Planejamento e avaliação; 
e políticas de atendimento a estudantes e egressos (SINAES, 2004). Estas dimensões devem fornecer os meios para o desenvolvimento, com eficiência, das atividades-fim: ensino, pesquisa e extensão.

Enfim, a avaliação é entendida como um mecanismo de autocontrole da consistência institucional, na medida em que faz um diagnóstico da situação atual, subsidiando o planejamento e a gestão institucional. (RISTOFF, 2004).

\section{Metodologia}

Este artigo é oriundo de um projeto de pesquisa que discute as incorporações, fusões e aquisições da Educação Superior do Brasil. Sendo assim, foi aplicado um questionário fechado a 100 gestores da Educação Superior de vários estados brasileiros.

A pesquisa é de caráter qualitativo e quantitativo, sendo que para este papper foi considerado analisar somente os dados quantitativos. Fonseca (2002, p. 20) afirma que a pesquisa quantitativa:

Diferentemente da pesquisa qualitativa, os resultados da pesquisa quantitativa podem ser quantificados. Como as amostras geralmente são grandes e consideradas representativas da população, os resultados são tomados como se constituíssem um retrato real de toda a população alvo da pesquisa. A pesquisa quantitativa se centra na objetividade.

A coleta de dados ocorreu no período de agosto/2017 a março/2018, em vários estados brasileiros. Os sujeitos da pesquisa foram gestores de Instituições de Ensino Superior privadas, tais como: reitores, diretores, pró-reitores, procuradores institucionais e coordenadores de curso. Foram realizados gráficos para melhor visualização dos dados coletados, quais foram analisados e discutidos, conforme a literatura vigente.

Considerando a ética necessária às pesquisas com seres humanos, o presente artigo obedece à Resolução nº 466/12, do Ministério da Saúde, de acordo com a qual os participantes são informados sobre os objetivos da pesquisa e só participam após anuência e consentimento de execução do estudo.

O presente artigo tem aprovação do comitê científico da Pontifícia Universidade Católica do Rio Grande do Sul - PUCRS, sob o número de protocolo da pesquisa nº 57/2012.

\section{Resultados e discussão}

Quando os gestores foram indagados sobre o SINAES, considerando se o sistema é democrático, igualitário e balizador da Educação Superior no Brasil, 32\% dos entrevistados discordam parcialmente da afirmação, ou seja, 32 gestores não estão de acordo parcialmente 
com a premissa, e $26 \%$ discordam do sistema. Assim sendo, mais da metade dos entrevistados não consideram o SINAES democrático, igualitário e balizador à Educação Superior brasileira, conforme demonstra o Gráfico 1.

Gráfico 1 - O SINAES é um sistema democrático, igualitário e balizador da Educação Superior no Brasil

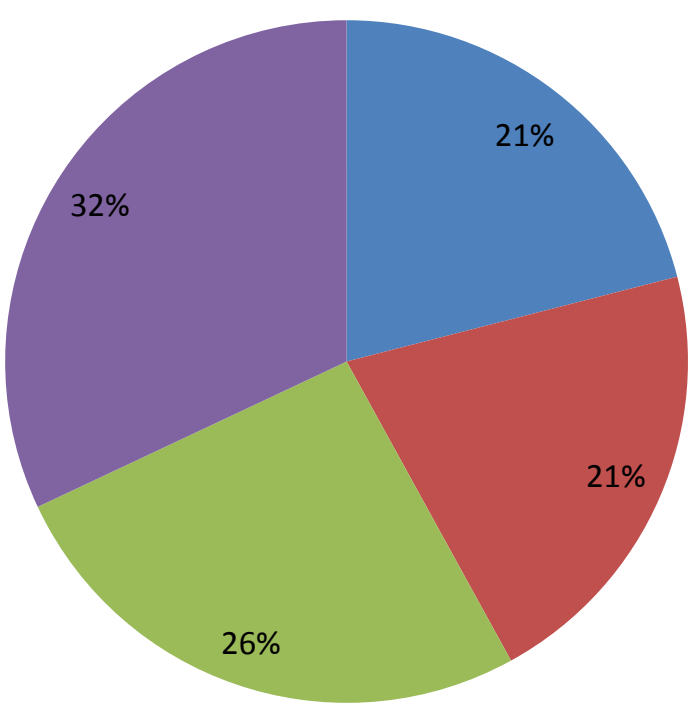

- Concordo

- Concordo Parcialmente

Discordo

- Discordo Parcialmente

Fonte: Elaborado pelos autores.

Percebe-se que existe uma disparidade entre a legislação em vigor, ora concretizada pelo sistema regulador da avaliação, e a implantação e efetivação deste sistema, frente às mutações ocorridas na educação. Os sistemas educacionais sofreram mudanças significativas que respondem ao atual cenário político, social e econômico, no qual se entende que este percentual esteja alicerçado, dentro dos parâmetros educacionais, onde a criticidade, por parte dos docentes e discentes, concretiza-se através de proposições, que ocorrem de forma gradativa e sequencial, de acordo com as constantes transformações ocorridas no cenário contemporâneo. Após a implantação do SINAES, ficou evidente um "costume negativo" das Instituições de Ensino Superior (IES), em relação a importantes dimensões do sistema, sobretudo em relação à autoavaliação, que era considerada o ponto de partida dos processos que constituem o sistema avaliativo.

Para 58\% dos gestores o SINAES não é um sistema democrático, igualitário e balizador da Educação Superior no Brasil. Para Frauches (2014, p.1): 
Atrelar a avaliação de qualidade da educação superior aos processos de regulação, como prevê o parágrafo único do art. $2^{\circ}$, traz para os processos avaliativos do Sinaes conflitos conceituais, processuais e procedimentais. A avaliação de qualidade é um processo permanente, contínuo que requer critérios e procedimentos específicos. A regulação é periódica e deve ter critérios próprios. O conflito entre "avalição de qualidade" e "regulação" tem contribuído, desde a implantação da Lei do Sinaes, para os conflitos e distorções observados nos dois processos.

Embora o SINAES seja um grande avanço em termos de avaliação no Brasil, observa-se que o Ministério da Educação ainda não qualificou os dados para a sociedade. O instrumento de avaliação ainda é quantitativo, não explicitando, de fato, se há qualidade na avaliação.

Outra acepção, permeada por Dias Sobrinho (2010), é que desde a sua proposta inicial, o SINAES prezou por princípios e compromissos caros à comunidade acadêmica, colhidos em várias audiências públicas, os quais determinam que a avaliação da Educação Superior não seja fragmentada, respeite a identidade institucional em suas etapas interna e externa.

Em outro viés, Zainko (2008, p. 831) evidencia problemas manifestados das mais variadas formas, tais como: problemas de origem política, falta de pessoal capacitado na abordagem do SINAES, ausência de reflexão interna e na própria questão da "cultura" de avaliação organizacional.

O SINAES é um caso singular de dessuetude pelo próprio Governo, que deveria zelar pela "fiel execução" da lei, conforme a Constituição Federal. (BRASIL, 1988, 84, IV). A dessuetude pelo Governo também ocorre quando este regulamenta as leis de forma "infiel" ao conteúdo original aprovado no Congresso, extrapolando o poder regulamentar de que trata o artigo 84, IV, da Constituição de 88. Em sentido conexo, Federici Gomes (2005, p 21) entende que o Decreto $n^{\circ} 5.773 / 2006$ (BRASIL, 2006), que regula o Sistema Federal de Ensino, e a Lei do SINAES, nas suas funções de regulação, supervisão e avaliação, trouxeram ilegalidades e desvirtuamentos que ultrapassam "os limites do poder normativo". Pode-se afirmar que as reformas no SINAES antecederam à sua criação, pois, ainda no Governo de Fernando Henrique Cardoso, foi definido que ao invés de deliberar "sobre processos", a Câmara de Educação Superior do Conselho Nacional de Educação passaria a deliberar "sobre normas" (BRASIL, 2001b, art. 9, §2, “d”, “e”). Embora não executada de imediato, a alteração mexeu em um dos princípios básicos da Educação pós - $\mathrm{CF} / 88$, o que trata da gestão democrática, tanto à definição de políticas públicas quanto à sua execução e avaliação. Analisando o assunto, Dalmolin (2012, p. 11) sustenta que "no contexto democrático supera-se a concepção de trabalhar para a comunidade e passe-se a trabalhar com ela."

Importa, ainda, recorrer à Lei do SINAES, ao mencionar que tanto na avaliação de cursos, quanto na institucional, deverão ser adotados "procedimentos e instrumentos diversificados". 
Não só a qualidade deve ser medida por diversos meios, como estes devem ser associados para averiguar e comprovar os dados necessários à tomada de decisão sobre o nível de qualidade almejado. Se o próprio Governo entende que os resultados das avaliações do SINAES não são determinantes, e sim referenciais básicos, é razoável que os conjugue a outros meios, adotando múltiplos indicadores para reforçar a qualidade verificada. Pelo exposto, é possível inferir que o SINAES passou por transformações profundas, tanto nos princípios e pressupostos, quanto nas formalidades, sobretudo com dispensas destas. Há sólidas evidências que autorizam falar de um sistema reformado, a merecer o adjetivo de novo, o qual denominamos de Neo SINAES.

Qualidade é conceito polissêmico, conforme concepções e interesses das arenas de poder da Educação Superior. Essas concepções têm assimetrias entre a iniciativa privada e o setor público, podendo mascarar pedagogias de gerenciamento e performatividade, abordando a qualidade na avaliação da Educação Superior como conceito em disputa entre a avaliação como um processo de caráter formativo e emancipatório e como um referencial básico da regulação. Essa disputa explícita a polissemia da qualidade na avaliação, ressaltando a perspectiva regulatória presente no sistema educacional brasileiro.

Para Lacerda (2015), o SINAES, hoje, convive com o desafio de ajustar-se a um modelo em que as dimensões qualitativas e quantitativas, ao invés de excludentes, se complementem. O autor sustenta que no sistema em tese, os movimentos das IES para "reflexão e autorregulação teriam papel central, mas que (...) em sua operacionalização, responde aos movimentos de produtividade, performatividade e alinhamento com o mercado profissional" (LACERDA, 2015, p.99). Para o autor citado acima, é impossível a dualidade quali-quanti quando a "subordinação de uma em relação à outra não esteja plenamente e claramente estabelecida. E essa falta de subordinação é que fez e faz com que o SINAES não possa respeitar seus próprios pressupostos.” (LACERDA, 2015, p.100)

Os dados confirmam que tanto a avaliação de cursos de graduação (bacharelados, licenciaturas e tecnológicos), presencial e à distância, quanto a institucional não possuem a notoriedade e intensidade conferidas pelo Ministério da Educação - MEC ao Exame Nacional de Desempenho dos Estudantes - ENADE.

Sua amplitude, por força discricionária e microrregulatória, ultrapassa as fronteiras definidas na Lei do SINAES e toca a densa maioria das atuais políticas da Educação Superior e os atos regulatórios. É possível concluir, sobretudo, que não obstante as contribuições das IES e do Governo à ineficiência do SINAES, entende-se que o sistema tem conquistas valorosas, com destaque à robusta produção de dados que podem subsidiar diagnósticos da Educação Superior e formulação de políticas. O fato é que a avaliação é irrevogável e a qualidade é um 
processo que envolve, compulsoriamente, Governo, Instituições de Ensino Superior - IES e Sociedade.

De acordo com dados contidos no Gráfico 2, 51\% dos entrevistados declararam discordar que a Portaria $n^{\circ} 40 / 2007$, complementada pelo Decreto $n^{\circ} 9.235 / 2017$, atenda às necessidades do Ensino Superior no Brasil. A Portaria n ${ }^{\circ}$ 40/2007, de 12 de dezembro de 2007, institui o eMEC, sistema eletrônico de fluxo de trabalho e gerenciamento de informações relativas aos processos de regulação da Educação Superior no Sistema Federal de Educação. Considerandose as respostas discordo e discordo parcialmente, chama-se a atenção que mais de $81 \%$ não concordam com os dispositivos permeados no SINAES.

Gráfico 2 - A Portaria no 40/2007 atende às necessidades do Ensino Superior no Brasil

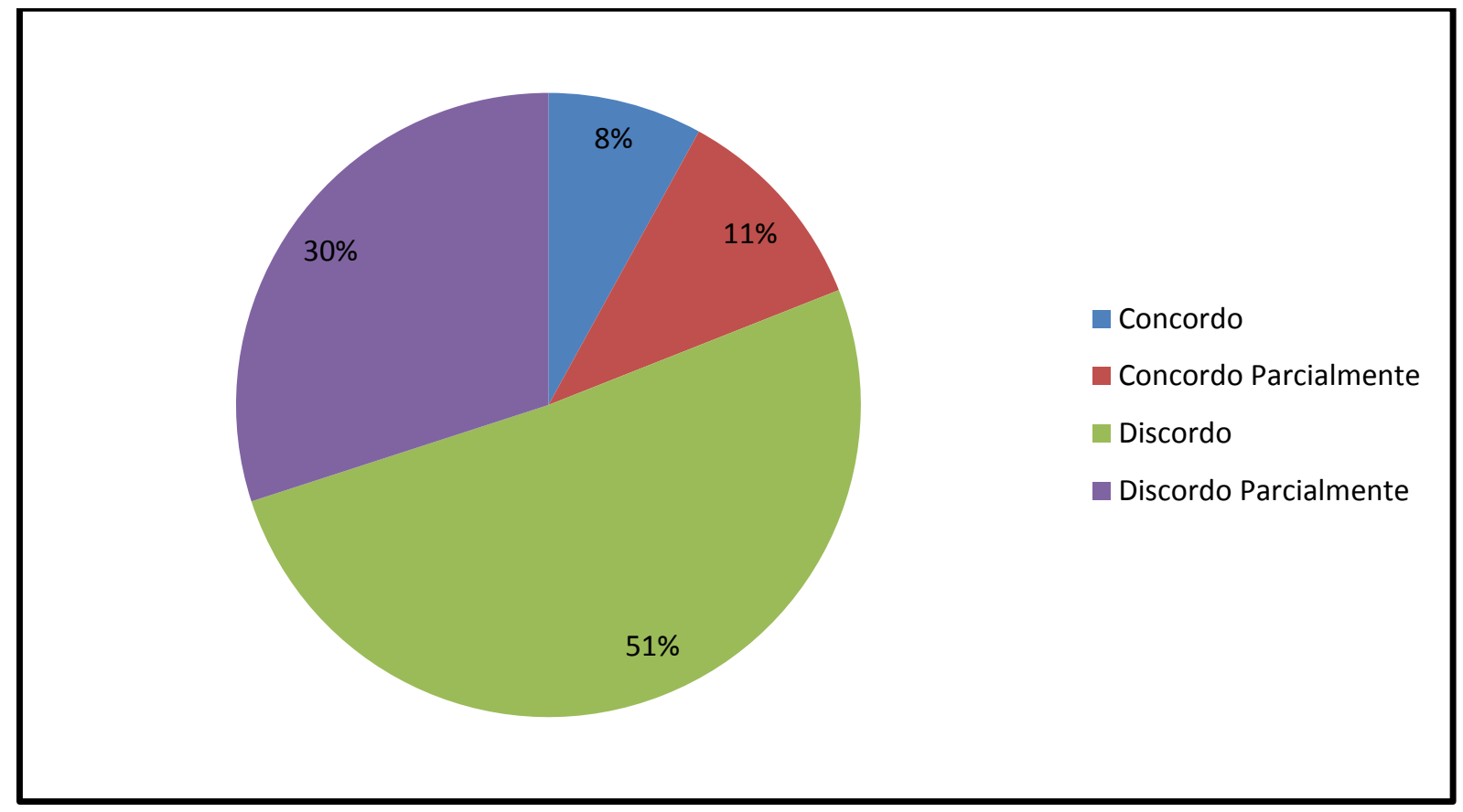

Fonte: Elaborado pelos autores.

Conforme a Associação Brasileira de Mantenedoras de Ensino Superior (ABMES), a republicação da Portaria Normativa n ${ }^{\circ}$ 40/2007, em 29 de dezembro de 2010, mostra mais uma vez o Ministério da Educação extrapolando os limites legais para sua atuação, usurpando competência legislativa que não possui e distorcendo princípios e normas legais para regular, impondo obrigações e restringindo direitos, por intermédio de atos normativos secundários e terciários.

Levando-se em consideração estes dados, onde são sinalizados que quase $80 \%$ dos gestores não concordam ou não concordam parcialmente, deve-se ao fato de que os mesmos são empregados de Instituições de Ensino Superior privadas e a Portaria que define a supervisão 
e a regulação da Educação Superior no Brasil é considerada rigorosa. Oliveira (2014) parafraseia que a partir de um critério mais rigoroso da supervisão e regulação da Avaliação Superior no Brasil, desde o SINAES, as IES de menor porte padeceram para atender as regulamentações vigentes. Com isto, muitas destas instituições de Ensino Superior (faculdades) foram incorporadas pelos grandes grupos educacionais.

Quando os pesquisadores afirmam que "O ENADE, o CPC e IGC são dispositivos democráticos nos processos avaliativos", $71 \%$ dos gestores discordam, ou seja, 71 deles estão em desacordo com a afirmação, conforme demonstra o Gráfico 3.

Gráfico 3 - O ENADE, o CPC e IGC são dispositivos democráticos nos processos avaliativos

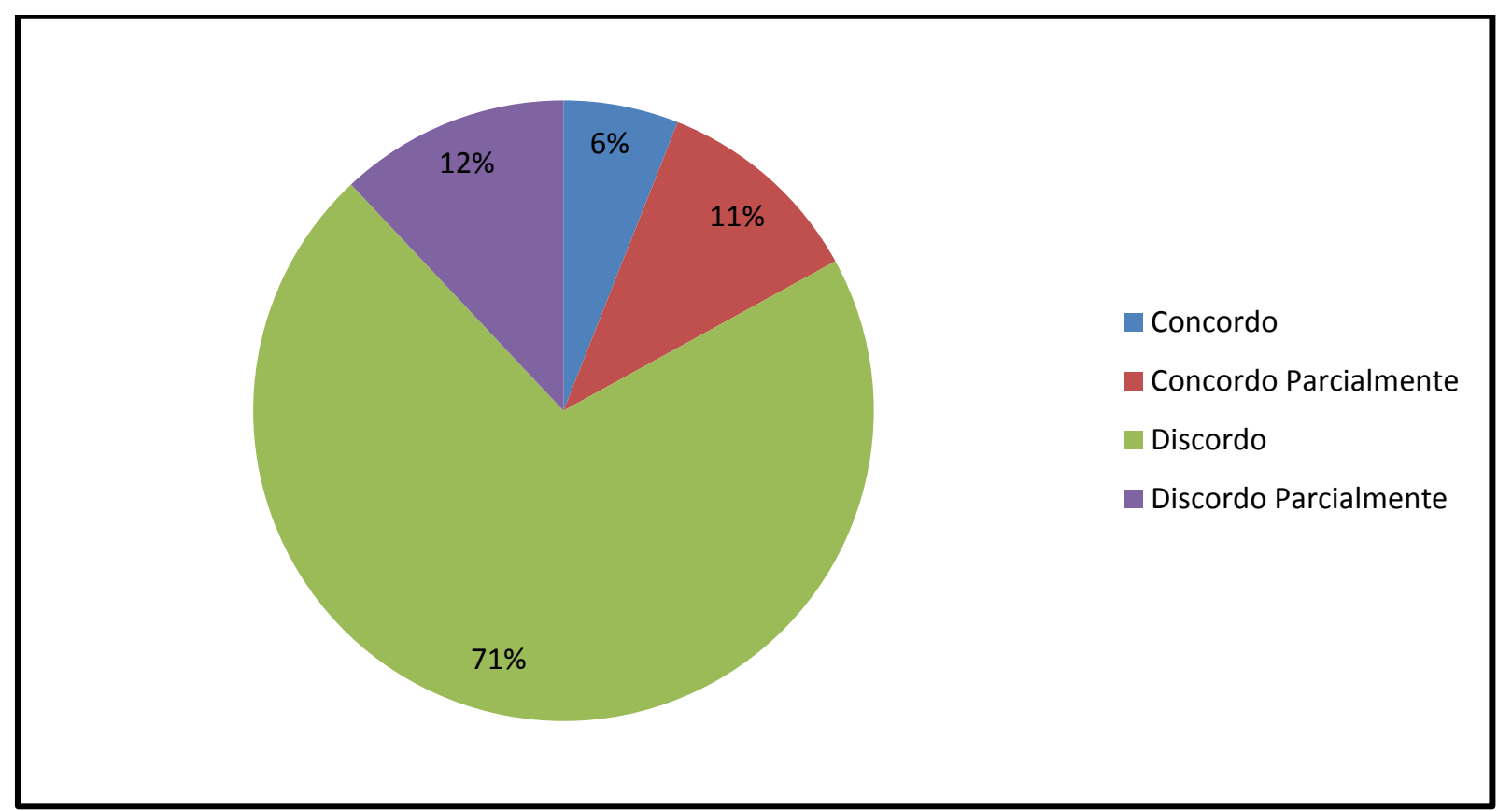

Fonte: Elaborado pelos autores.

O Sistema Nacional de Avaliação de Ensino Superior (SINAES) prevê que o Ensino Superior será avaliado, considerando: a instituição de ensino; os cursos ofertados e os alunos ingressantes e concluintes. Para tanto, o SINAES criou uma tríade de avaliações, com o intuito de atender às três áreas já citadas, que tem seu início com a Avaliação Institucional, passando pela Avaliação de Curso e sendo encerrada com o ENADE, considerando o que estabelece o art. $2^{\circ}$, incisos I a IV:

1. Avaliação institucional, interna e externa, contemplando a análise global e integrada das dimensões, estruturas, relações, compromisso social, atividades, finalidades e responsabilidades sociais das instituições de educação superior e de seus cursos;

2. O caráter público de todos os procedimentos, dados e resultados; 
3. O respeito à identidade e à diversidade de instituições e de cursos;

4. A participação do corpo discente, docente e técnico administrativo das instituições de educação superior, e da sociedade civil, por meio de suas representações.

Em conformidade com os dados descritos no Gráfico 03, 83\% dos entrevistados afirmaram que discordam ou discordam parcialmente que o ENADE, o CPC e IGC são dispositivos democráticos nos processos avaliativos. O CPC e IGC estão intimamente ligados ao resultado do ENADE, e embora os estudantes sejam obrigados a fazer a prova, eles não têm com ela um compromisso, haja vista que seu resultado, positivo ou não, em nada interfere na formação do graduando, ainda que este entregue a prova em branco, apenas para efeito de registro no histórico escolar. Outro fator que torna os critérios avaliativos autocráticos é que seus resultados deveriam servir como referência para as comissões in loco nas avaliações das IES e de cursos, no entanto, ainda que sejam apenas indicadores, não representado conceitos previstos em lei, passaram a ser utilizados para os mais diversos fins, como permitir ou não que a IES mantenha vínculo com o FIES, Prouni, para arquivamento de processos de autorização de cursos propostos pelas IES, reduzir autonomia, proibir novos processos seletivos, reduzir número de alunos. As IES não têm acesso imediato às Notas Técnicas que embasam tais decisões.

O ENADE tem como objetivo avaliar o desempenho dos estudantes com base no nível de atualização em relação à realidade mundial e brasileira, nos conteúdos previstos nas diretrizes curriculares e o desenvolvimento de competências e habilidades necessárias ao aprofundamento da formação geral e profissional. É a base de todo o sistema de avaliação de cursos e instituições.

Segundo Scaglione e Costa (2011), é correto afirmar, ainda que de maneira simplificada, que todos esses índices se apoiam no ENADE. Devido à falta de comprometimento dos estudantes para a realização da avaliação, pode prejudicar o sistema consideravelmente. Por essa razão, Frauches (2018) defende que o ENADE não pode ser tomado como avaliação de qualidade de um curso de graduação, sem considerar as condições de oferta.

O CPC, Conceito Preliminar de Curso, é composto pelo conceito do ENADE, pelo IDD - Indicador de Diferença entre os Desempenhos Observado e Esperado -, por titulação e regime de dedicação do corpo docente, percepção dos alunos com relação à infraestrutura e a organização didático-pedagógica, que são avaliados através de questionário socioeconômico antecedente ao ENADE. É um conceito preliminar, pois com base nos seus indicadores, o MEC decide pela necessidade ou não de realização da avaliação externa in loco das condições de 
oferta. Scaglione e Costa (2011, p. 6) afirmam que sendo assim, não parece correto dar a um conceito preliminar o status definitivo, muito menos organizar um ranking com ele.

O IGC, Índice Geral de Cursos, tem a pretensão de avaliar a qualidade das instituições de ensino. Utiliza, para o cálculo, a média ponderada de todos os cursos de graduação e as avaliações da CAPES, para os cursos de pós-graduação stricto sensu.

A última afirmação da pesquisa contempla a premissa “A avaliação da Educação Superior do Brasil é parametrizadora de qualidade e de estratégia às IES", 76 gestores discordam desta afirmativa, ou seja, 76\% não estão de acordo com a afirmação da pesquisa como demonstra o Gráfico 4.

Gráfico 4 - A avaliação da Educação Superior do Brasil é parametrizadora de qualidade e de estratégia às IES

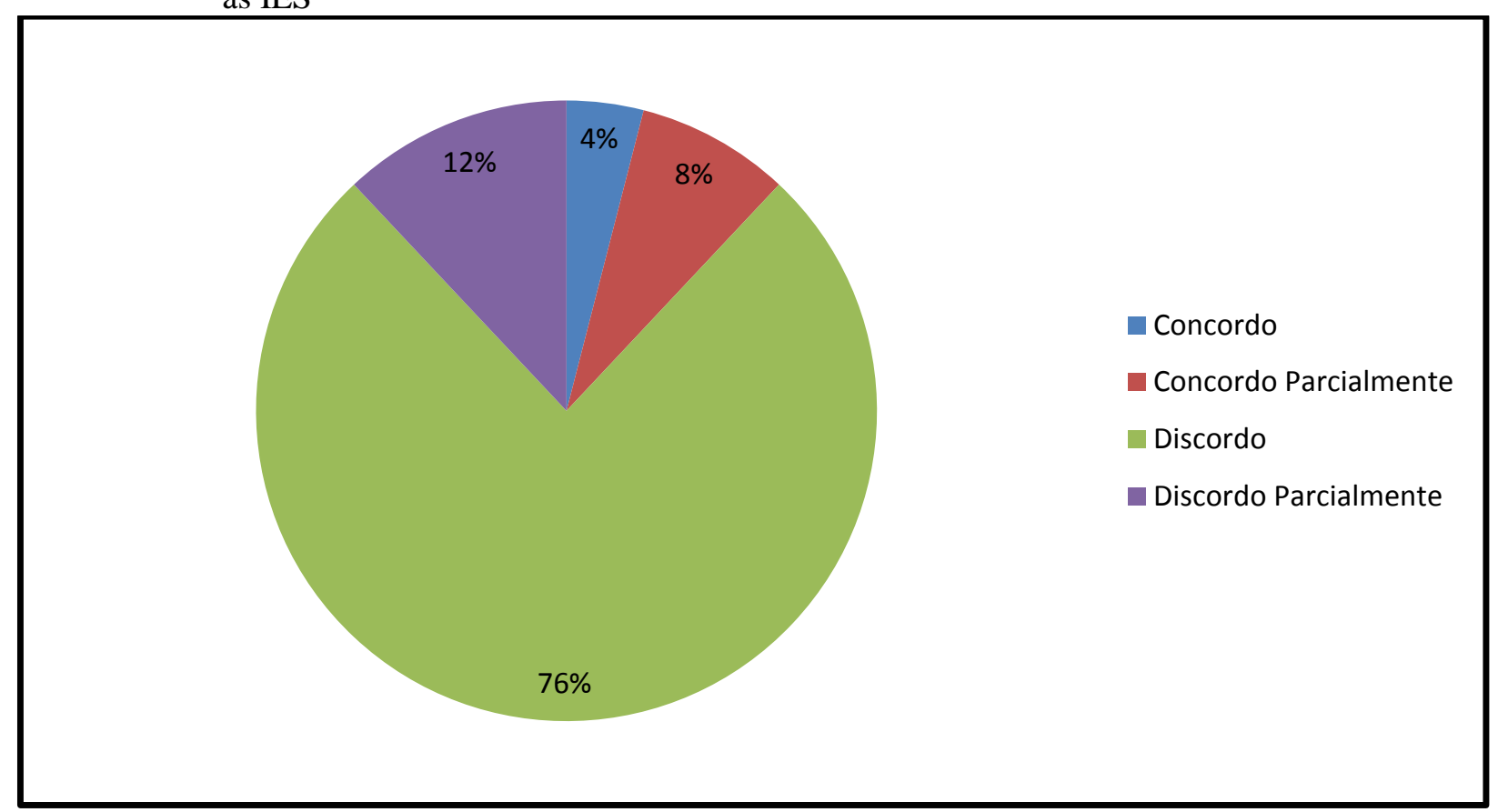

Fonte: Elaborado pelos autores.

As mudanças socioeconômicas e culturais que vêm ocorrendo no mundo inteiro, com especial atenção ao desenvolvimento da tecnologia da informação, têm sido percebidas, com maior ênfase, nas últimas duas décadas, vêm impulsionando a busca por conhecimento e estimulando o ingresso no Ensino Superior. No Brasil, o que se pôde observar foi a ascensão de classes menos favorecidas, que a partir dessas mudanças conseguiram ter acesso também ao Ensino Superior.

Acompanhando a crescente demanda de um público alvo novo no Ensino Superior, houve uma expansão da iniciativa privada no setor educacional, a partir do final da década de 90 . 
Conforme Censo da Educação Superior de 2017, INEP/MEC, o Brasil tem mais de 2400 IES, deste total, $88 \%$ são particulares. O crescimento do setor foi tão grande, que possibilitou observar que o aumento de vagas em cursos superiores foi maior que o número de ingressantes, ocasionando capacidade ociosa, especialmente nas IES privadas.

Uma das causas dessa disparidade passa pela Constituição Federal Brasileira/1988, por meio do artigo 209, que permite a abertura de IES pelo Brasil inteiro, e autoriza que o ensino seja livre à iniciativa privada, desde que atendidas às condições de cumprimento das normas gerais da educação nacional e autorização e avaliação de qualidade pelo Poder Público.

Inclui-se aí um ponto que merece reflexão: o governo, impossibilitado de atender à grande demanda reprimida por Educação Superior viu-se obrigado a abrir mercado para a iniciativa privada. Com isso, expandiu o sistema educacional e agora encontra dificuldades para cumprir sua missão de avaliar a qualidade.

O aumento do número de estudantes vem provocando disputas e tornando o ambiente educacional do país altamente competitivo. Em contrapartida, a qualidade de muitas instituições está decaindo consideravelmente, com o advento da competitividade (CONSONI; HENRIQUES, 2011). A obrigação de fiscalizar as IES é do governo, que, devido a essa expansão, vem encontrando sérias dificuldades de cumprir sua missão.

A Lei do SINAES foi reduzida à simples determinação de índices - ENADE, CPC e IGC, que, aplicados a um sistema em rápida ascensão, acabou gerando distorções. Isso se deve à grandiosidade do sistema de educação brasileiro e à aspiração do MEC de controlar tudo. Esses índices vêm sendo vistos como a representação numérica da qualidade. As variáveis que compõem os índices de qualidade citados são medidas através do desempenho acadêmico de formandos, infraestrutura, titulação do corpo docente e da condição sociocultural dos alunos. Essas variáveis são indiscutivelmente importantes para a formação do conceito de qualidade institucional, todavia, as distorções aparecem quando, com base em tais índices, são formados rankings, que reduzem tudo a números, desconsiderando os princípios do SINAES no que tange à diversidade do sistema, o respeito à identidade, à missão e à história das instituições, e divulgando para a sociedade um resultado aceito como sendo de grande relevância.

Quando o SINAES foi criado, não houve a intenção de que a avaliação de qualidade fosse reduzida a índices. Esses índices simplificaram a forma de se comparar qualidade, pois num cenário novo, em que a competitividade está em alta, com uma vasta gama de cursos e instituições, torna-se muito simples comparar as notas das IES para escolher qual a melhor.

Dias Sobrinho (2010) alerta para a tendência de exames nacionais transformarem a relação didático-pedagógica em mero treinamento de estudantes para a prova, induzindo 
currículos, reduzindo espaço para a construção reflexiva e desenvolvimento dos cursos. Isso já pode ser observado na prática. Instituições de ensino estão adaptando seus programas e desenvolvendo estratégias de preparação dos alunos para o ENADE, a fim de alavancar bons resultados, devido à preocupação com o efeito negativo de uma posição desfavorável no ranking.

\section{Considerações finais}

Pesquisar olhares é discernir uma dimensão subjetiva humana, por meio de uma percepção singular na categorização estudada. Cinge-se que boa parte dos gestores discorda da forma como a avaliação do Ensino Superior é realizada no Brasil, observou-se conjecturandose que as percepções não são aleatórias, uma vez que o Ministério da Educação - Instituto Nacional de Estudos e Pesquisas Anísio Teixeira (INEP) até os dias atuais não sinalizaram dados qualitativos no que concerne à qualidade da Educação Superior no Brasil. Tratar censo anualmente não significa e nem sinaliza à sociedade se há uma qualidade desta educação.

Há muitas críticas, de diferentes pesquisadores envolvidos na educação, porém, há elogios, embora incipientes. Um agravante a ser considerado são as inúmeras mudanças de ministros de Educação nas mudanças de governo que, sinalizam lógicas diferenciadas de avaliação, trazendo às IES conflitos para atender às demandas diversas na avaliação, no zelo das IES, a fim não serem punidas no processo avaliativo.

Outro cerne a ser considerado é que o instrumento é meramente técnico, sendo assim fácil de ser burlado, na incessante busca de um conceito satisfatório à IES e ao curso de graduação. Recentemente, foi promulgado o Decreto $n^{\circ}$ 9.235/2017, que redefine novos parâmetros de avaliação. Este mote se deu por meio de uma solicitação das Instituições de Ensino Superior privadas no governo Temer, numa perspectiva de atender à lógica da mercantilização do Ensino Superior no Brasil.

São estas searas que fragilizam as políticas públicas educacionais brasileiras, conjecturando-se no momento a qualidade do Ensino Superior. Estas indagações e refutações são sustentadas nas falas dos gestores investigados nesta pesquisa sobre as incorporações, fusões e aquisições na Educação Superior do Brasil.

O cenário atual comunga para uma fragilidade nas políticas públicas da Educação Superior, face que há um declínio na Educação Superior Brasileira, no que diz respeito à supervisão e regulação da Educação Superior no Brasil. Existe uma certa tendência no campo 
politico atual de favorecer as Instituições de Ensino superior privadas com o fortalecimento da Associação Brasileira de Mantenedores da Educação Superior (ABMES).

\section{Referências}

ABMES: Associação Brasileira de Mantenedoras do Ensino Superior: A republicação da Portaria Normativa $n^{\circ}$ 40/2007. Disponível em: https://blog.abmes.org.br/?p=1468> Acesso em 04 de out. 2018.

BRASIL. Constituição (1988). Constituição da República Federativa do Brasil. Brasília, DF: Senado Federal: Centro Gráfico, 1988. 292 p.

BRASIL. Decreto n. 9.235, de 15 de dezembro de 2017. Dispõe sobre o exercício das funções de regulação, supervisão e avaliação das instituições de educação superior e dos cursos superiores de graduação e de pós-graduação no sistema federal de ensino. Disponível em: http://www.planalto.gov.br/ccivil_03/_Ato2015-2018/2017/Decreto/D9235.htm> Acesso em 05 out. 2018.

BRASIL. Lei 9394, de 20 de dezembro de 1996. Estabelece as Diretrizes e Bases da Educação Nacional. Disponível em: http://www.planalto.gov.br/ccivil_03/LEIS/L9394.htm> Acesso em 05 out. 2018.

BRASIL. Lei 10861, de 14 de abril de 2004. Institui o Sistema Nacional de Educação Superior - SINAES e dá outras providências. Disponível em: <http://www.planalto.gov.br/ccivil_03/_ato2004-2006/2004/lei/110.861.htm>. Acesso em 04 out. 2018.

CONSONI, F.; HENRIQUES, F. Formação de Recursos Humanos e educação superior: $O$ papel do conhecimento como estratégia de desenvolvimento no estado de São Paulo, 2011.

DALMOLIN, A. M. T. Avaliação institucional e gestão democrática na educação superior brasileira, segundo dois periódicos da área da educação. In: IX Seminário de Pesquisa Educação da Região Sul - ANPEDSUL. Caxias do Sul. ANAIS DA IX ANPEDSUL. Caxias do Sul: UCS, 2012. p. 1-18.

DIAS SOBRINHO, J. Avaliação e transformações da educação superior brasileira (19952009): do Provão ao SINAES. Avaliação: Revista da Avaliação da Educação Superior, v.15, n.1. 2010. p.195-224.

DIAS SOBRINHO, J. Avaliação da educação superior: avanços e riscos. EccoS Revista Científica, v. 10, n. Esp, 2008. p. 67-93.

FEDERICI, G. M. Supervisão e avaliação da educação superior. Brasília: Revista Brasileira de Estudos Pedagógicos - RBEP, v. 90, n 225. 2005.

FONSECA, J. J. S. Metodologia da pesquisa científica. Fortaleza: UEC, 2002. Apostila.

FRAUCHES, C. C. Comentários e Anotações Preliminares para um Conceito Preliminar. Revista da Associação Brasileira de Mantenedoras de Ensino Superior, n.38. 2008. p.33- 42. 
FRAUCHES, C. C. Sinaes: 10 anos de acertos e Desacertos. Revista da Associação Brasileira de Mantenedoras de Ensino Superior, n.38, 2014, p.1.

LACERDA, L. L. V. Sinaes, teoria e prática: pressupostos epistemológicos em oposição. Avaliação (UNICAMP), v. 20. 2015. p. 87-104. Disponível em: http://www.scielo.br/pdf/aval/v20n1/1414-4077-aval-20-01-00087.pdf> Acesso em: 06 out. 2018.

OLIVEIRA, F. N. G. Um dispositivo cogente nas instituições de ensino superior: uma reflexão teórica sobre a gestão de conhecimento. Revista Eventos Pedagógicos, v. 5 2014. p. 20-34.

POLIDORI, M. M; MARINHO-ARAUJO, C. M.; BARREYRO, G. B. SINAES: perspectivas e desafios na avaliação da Educação Superior brasileira. Ensaio, v. 14, n. 53. 2006 p. 425436.

POLIDORI, M. M. Políticas de avaliação da educação superior brasileira. Avaliação: Revista da Avaliação da Educação Superior, v. 14, n. 2, 2009.

RISTOFF, D. Universidade em foco: reflexões sobre a educação superior. Florianópolis: Insular, 2003.

SCAGLIONE, V. L. T.; COSTA, M. N. Avaliação da Educação Superior e Gestão Universitária: Padrões de qualidade definidos pelas Instituições de Ensino Superior, pelo MEC e pela sociedade, incluindo ENADE, IDD, CPC e IGC. 2011. Disponível em: https://repositorio.ufsc.br/bitstream/handle/123456789/25965/2.12.pdf?sequence=1\&isAllowe $\mathrm{d}=\mathrm{y}>$ Acesso em 06 de out. 2018.

ZAINKO, A. S. Avaliação da Educação Superior no Brasil: Processo de construção histórica. Avaliação, Campinas; Sorocaba, SP, v. 13, n 3. 2008. Disponível em: http://www.scielo.br/pdf/aval/v13n3/12.pdf> Acesso em: 05 out. 2018. 